Ana Huber*

Filološki fakultet

Univerzitet u Beogradu

Doktorantkinja
371.3::811.134.2'243

https://doi.org/10.18485/zivjez.2020.40.1.3 Оригинални научни рад

\title{
MIZOGINIJA I SEKSIZAM U REKLAMAMA NA SRPSKIM TELEVIZIJAMA
}

Tema rada je prisustvo mizoginije i seksizma u televizijskim reklamama koje obiluju rodnim stereotipima. Analizirani korpus čine reklame emitovane $\mathrm{u}$ Srbiji na televizijama sa nacionalnom frekvencijom $\mathrm{u}$ periodu od jeseni 2018. do leta 2020. godine, uz nekoliko starijih reklama koje su poslužile kao ilustrativni primeri. Sa feminističkog stanovišta će se ispitati kojim se lingvističkim i persuazivnim sredstvima postiže izvestan stepen rodne diskriminacije u reklamnim spotovima. Cilj rada je da se kroz kvalitativnu analizu korpusa reklama pruži dokaz o zastupljenosti mizoginih i seksističkih diskursa i vizuelnih efekata u reklamnim spotovima, čak i kada se kroz reklame prividno propagira emancipatorski stav prema ženskom pitanju. Osim seksizma i stereotipije, takođe posmatramo diskriminaciju prema godištu i socijalnom statusu. Ispituje se kako jezik reklama odražava društveni poredak i oslikava stereotipne društvene odnose i da li, čak i kada formalno tvrdi suprotno, učvršćuje ustaljene rodne uloge. Rezultati analize ukazuju da reklame imaju jak psihološko-sociološki efekat i da oblikuju poželjne modele ponašanja i ideologije.

Ključne reči: mizoginija, seksizam, televizijske reklame, feminizam, rodni stereotipi, rodne uloge.

\section{Uvod}

Masovni mediji, uključujući i reklame, predstavljaju ogledalo društvene stvarnosti, ali su i njeni primarni projektanti (Višnjić i Mirosavljević 2008: 248). Od svog nastanka polovinom XX veka

*anahuber9295@gmail.com 
pa do danas, televizijska reklama je kompleksan oblik propagande i kulturni fenomen. U početku su se proizvođači zadovoljavali jednostavnim parolama ili pukim ponavljanjem zaštićenih naziva proizvoda (Beri i saradnici 1968: 286), ali tržište danas traži više inventivnosti.

Televizijska reklama danas se definiše kao „kratka forma medijskog zagovaranja, čiji je cilj promocija određenog proizvoda“ (Valić Nedeljković 2008: 151). U većini slučajeva, reklame imaju sličnu strukturu. Pored slika, ilustracija i muzike kao vizuelnoauditivne komponente, jezički elementi reklame su: natpis, „telo“ reklame (engl. body copy, odnosno suština reklamne poruke), slogan, ime proizvoda i važni detalji o proizvodu (Piler 2003: 172). Unutar ove strukture moguće su varijacije.

Fokus ovog rada jesu televizijske reklame u kojima je izražen aspekt mizoginije ili seksizma. Analiziraju se sa stanovišta feminizma, kritičke sociolingvistike i feminističke lingvistike ${ }^{1}$. Korpus za analizu čine reklame koje su se emitovale na srpskim televizijama sa nacionalnom frekvencijom između jeseni 2018. godine i leta 2020. godine, uz nekoliko starijih reklama koje su poslužile kao ilustrativni primeri. Na taj način se potkrepljuje teza da mizogini diskurs predstavlja konstantu u reklamnoj strukturi, čak i kada se prividno propagira emancipatorski stav prema ženskom pitanju. Cilj ovog rada je da ukaže ne samo na izrazitu mizoginiju u televizijskim reklamama, čime su se istraživači već bavili (Bašaragin 2013, Del Sas-Rubio i Penok-Spek 2009a, Dragićević Šešić 2002, Silaški 2010), već na generalno seksističku, stereotipnu i degradirajuću konstrukciju rodnih uloga i identiteta, zasnovanu na rodnim stereotipima.

U centru pažnje su mizogine reklame, ali i one seksističke. Objašnjava se kojim se lingvističkim i persuazivnim sredstvima postiže izvestan stepen rodne diskriminacije u reklamnim televizijskim spotovima. Putem kvalitativne analize reklama, pružaju se dokazi o zastupljenosti mizoginih diskursa i vizuelnih

1 Hana Ćopić definiše feminističku lingvistiku kao disciplinu koja postavlja pitanje na koji se način žene pojavljuju u jeziku i zastupa stanovište da se žene putem jezika sistematski tlače (2008: 237). 
efekata u reklamnim spotovima. Iako su u pitanju kratke forme, one su vrlo kompleksne i mogu da prenose snažno ideološki obojene poruke, koje imaju veliki uticaj na masovnu publiku. Kao i sve diskurzivne prakse, i reklame pomažu u stvaranju i reprodukovanju odnosa među društvenim grupama (Kuzmanović Jovanović 2013: 11), u ovom slučaju održavanju neravnopravnosti među polovima. U nastavku istražujemo kako se mizoginija reflektuje u verbalnim, a kako u vizuelnim komponentama reklame.

Identifikovanje rodnih stereotipa, mizoginije i seksizma veoma je važno kako bi se uticalo na formiranje i prenošenje rodnih ideologija (Kuzmanović Jovanović 2013: 35) odnosno na njihovo preispitivanje i transformaciju. Zato je vrlo značajno da se tako moćan medij kao što je televizijska reklama kritički i naučno opservira.

\section{Osnovni pojmovi}

Pojam mizoginije često se laički poistovećuje sa seksizmom, iako postoji razlika između ovih odrednica. Mizoginija se definiše kao „mržnja prema ženi i omalovažavanje svega što je žensko, negiranje žene i njenih vrednosti“ (Jarić i Radović 2011: 105). Seksizam je pak širi pojam koji obuhvata „diskriminaciju prema polu u nekoj društvenoj zajednici, bilo da je reč o muškarcima bilo da je reč o ženama" (Savić 2002: 65). Daleko češće nego na mržnji, mizoginija i seksizam zasnivaju se na propagiranju određenih rodnih uloga $i$ identiteta, koji počivaju na rodnim stereotipima.

Rodni stereotipi su „široko rasprostranjena, nekritički prihvaćena, samopodrazumevajuća mišljenja o ulogama i poziciji koju žene i muškarci treba da imaju u društvu“ (Jarić i Radović 2011: 155) odnosno „strukturirane mentalne kategorije o muškarcima i ženama zasnovane na preteranim, netačnim i rigidnim generalizacijama" (Stojanović 2014: 5). Oni su zasnovani na nekom prototipu iz stvarnosti koji nije univerzalno primenljiv (Mils 2008: 126-127).

Rodne uloge su ,skup očekivanja zajednice vezanih za ponašanje pojedinaca/pojedinki u odnosu na njihovu polnu pripadnost" (Jarić 
i Radović 2011: 152) i one u velikoj meri određuju rodne identitete, koji se odnose na ,,socijalnu i ličnu percepciju pojedinca o pripadanju ili nepripadanju vlastitom biološkom polu“ (Jarić i Radović 2011: 152-153). Rodni identiteti nisu unapred zadati, već se oblikuju u diskursu (Gvozdanović 2010: 225). Skup verovanja koji upravlja učešćem ljudi u rodnom poretku i njihovim rodnim ulogama naziva se rodna ideologija (Kuzmanović Jovanović 2013: 27). Masovni mediji snažno utiču na to kakva će se rodna ideologija uspostaviti kao dominantna i poželjna. Najveća snaga tako promovisane ideologije leži u tome što može da se nametne kao „prirodno stanje stvari“ (Kuzmanović Jovanović 2013: 27).

Mizoginija i seksizam dominantni su u patrijarhalnim društvima, gde u strogo utvrđenoj hijerarhiji muškarci dominiraju nad ženama (Jarić i Radović 2011: 120), ali ove pojave se mogu shvatiti i kao opšta karakteristika savremenog, globalizovanog društva. Muške odlike vrednuju se pozitivno i cenjene su, dok se ženske potcenjuju i negativno percipiraju (Irigare 1998: 120).

U svetu reklamnog oglašavanja, zasnovanom na površnosti i tipiziranosti, najčešće se poseže za stereotipnim predstavama o bilo čemu, pa tako i o polu i rodu. Od kratkih i jednostavnih slogana, TV reklame su postale složeni psihološki mehanizmi koji koriste suptilne i pažljivo osmišljene tehnike kako bi pridobili potrošače. Kada je mizogini diskurs prisutan u javnom istupanju poput reklame, on dobija izvesnu moć i postaje institucionalizovan. Svet advertajzinga je generalno izrazito maskulinizovan (Mekrobi 2009: 82), što ćemo pokušati da dokažemo analizom korpusa reklama u ovom radu.

\section{Korpus reklama}

Analizirani korpus u ovom radu čine reklame koje su se emitovale u Srbiji na televizijama sa nacionalnom frekvencijom (Happy, O2², Pink, Prva, RTS1, RTS2) u periodu od jeseni 2018. godine do leta 2020. godine. Odabrali smo reklame za koje smo ustanovili da se emituju u marketinškim blokovima više od pet

2 U martu 2020. godine televiziji 02 vraćeno je ime B92. 
puta dnevno, u različitim terminima između osam časova ujutru i dvadeset tri časa uveče, odnosno u takozvanom prajm tajmu ${ }^{3}$ i u delovima dana kada je gledanost obično manja. Nismo pravili razliku između domaćih reklama i inostranih reklama prevedenih na srpski jezik za potrebe našeg tržišta.

U prvoj fazi praćenja i beleženja primetili smo oko šezdeset reklama sa naznakama mizoginije, seksizma i drugih oblika diskriminatornog diskursa koji su tema našeg istraživanja. Tokom samog rada javila se potreba za uključivanjem što ilustrativnijih primera, pa smo se opredelili da na pojedinim mestima pomenemo i neke reklame emitovane pre 2018. godine, za koje smo smatrali da najvernije oslikavaju određene pojave. Rukovodili smo se time da u rad uvrstimo samo reklame koje je moguće pogledati na platformi YouTube. Krajnji korpus čini pedeset reklama za koje smo ustanovili da predstavljaju elemente mizoginog i seksističkog javnog diskursa (v. Dodatak).

\subsection{Mizogini i seksistički prikazi u reklamama}

Milena Dragićević Šešić (2002: 379-385) sastavila je listu tipskih ličnosti žene u masovnoj kulturi, koje su vidljive i u reklamama. Podelila ih je na:

I Negativne:

- Glupača

- Poslovna žena

- Seksualni objekat

- Brbljivica

- Ružna žena
II Pozitivne:

- Žrtva i majka

- Skromna i naivna

- Radoznala

- Sluškinja i sekretarica

U reklamama je u prvom planu žensko telo i ističe se njen fizički izgled, kao i njena poniznost pred muškarcem i želja da mu udovolji. Dakle, žena je u podređenom položaju u odnosu na muškarca, i fizički i psihički.

3 Večernji termini. 
Mizoginija je odavno inkorporirana u kulturu, pa tako i same žene prenose mizogine sadržaje, u kojima se prikaz ženskosti bazira na liku i telu, a ne liku i delu (Višnjić i Mirosavljević 2008: 250). Primer je reklama za preparat za mršavljenje biomed 4, u kojoj je prikazano kako mršava devojka ismeva debelu jer zbog debljine ne može da uđe u autobus prepun ljudi. Proizvođač sugeriše da lepota i vitkost garantuju uspeh i da lepi i mršavi bolje prolaze u životu i lakše savladavaju prepreke. Publika u većini slučajeva nije svesna da je neka reklama mizogina jer je mizoginija upakovana u tradicionalne obrasce i prihvata se kao normalan iskaz (Dragićević Šešić 2002: 371) ili čak duhovit, kao u pomenutoj reklami. Prikaz domaćice danas je često zamenjen stereotipom o zaposlenoj majci u žurbi, kojoj su određeni proizvodi neophodni da bi preživela dan (Mils 2008: 127). Primer je reklama za Naksi radio, gde žena u gužvi beži od obaveza i bori se sa stresom samo pomoću muzike sa ove stanice.

Daleko ekstremniji primer predstavlja reklama za sredstvo za smirenje tensilen, gde jedna majka tvrdi da ponovo uživa u svojoj porodici zahvaljujući tabletama. Ovde se javlja stereotip o histeričnoj ženi koja ne ume da se kontroliše i kojoj treba neki nametnuti faktor da bi se umirila. U reklami za Idea supermarkete samo su žene kupci. One kupuju tipične „domaćičke“ proizvode i to ih usrećuje. Specifično je to što su sve mlade, moderno obučene i igraju uz feminističku pesmu No roots Alis Merton, koja peva o slobodnoj ženi koja ne želi da se „ukoreni“. Ovaj reklamni spot je dobar primer koliko je svaki segment, od vizuelnog do muzičkog, pažljivo promišljen i psihološki efektan. Uz slogan „Vredno je zajedno“, ženama se sugeriše da bi njihove stereotipne uloge i obaveze trebalo da ih oduševljavaju. Ovakvi prikazi modernih, zauzetih žena nisu pokazatelj emancipacije već kvaziemancipacije (Višnjić i Mirosavljević 2008: 253). Reklame kao dominantni javni diskursi mogu da prikrivaju stvarne društvene odnose, da prividno slave ženskost, a da zapravo ponavljaju stereotipe o rodnim ulogama (Kuzmanović Jovanović 2013: 12, 19).

Reklame čak uspevaju da feminizam „prodaju“ kao stil i pozu, predstavljajući prividno jake žene (npr. reklama za vodu mivela, 
gde je žena energična, lepa i u formi zahvaljujući tom proizvodu). Reklame u kojima su žene u stalnom „ratu“ protiv umora, bora, celulita ili bilo čega drugog zapravo odražavaju androcentričan pogled na svet (Silaški 2010: 323-324). Primeri su reklame za herbafast fajber sredstvo za mršavljenje, gde se pojavljuje zgodna devojka u donjem vešu, kao i za limes anticelulit gel, gde se više puta ponavlja da je neophodno „ratovati i boriti se“ protiv celulita. Žensko telo je prikazano kao erotizovani objekat sa vrlo eksplicitnim mizoginim predstavama (Nenić 2008: 271) jer je žena sve vreme naga, sa vitkom figurom kao jedinim važnim svojstvom. Medijska slika žene u prvi plan najčešće stavlja njen fizički izgled, a ne karakter, sposobnosti i talente. Žene nisu predstavljene kao kompleksne ličnosti sa interesovanjima, znanjima i veštinama (Kuzmanović Jovanović 2012: 44). Ipak, zanimljivo je pomenuti jednu reklamu iz 2000. godine, u kojoj je napravljena parodija na tipične reklame za deterdžent sa domaćicama. Naime, jednostavna devojka (koju glumi Milena Pavlović, u tom trenutku vrlo popularna glumica) žali se na fleke koje godinama ne može da skine i pokazuje majicu sa likom tadašnjeg predsednika Slobodana Miloševića. Ova reklama je zapravo bila deo kampanje Otpor za izlazak na izbore 24. septembra 2000. godine. Kroz nju je prikazano da i obična žena može imati vrlo jasan politički stav i pozvati druge na pobunu.

\subsection{Dominantan uzoran muškarac i potčinjena ismejana žena}

Mizogine reklame prikazuju ili ženu u interakciji sa muškarcem, gde je on dominantan, ili samu ženu, koja je uvek uslužna i ljubazna. U reklami za mobilnu telefoniju vip1, muž ide na posao, vozi automobil, popravlja uređaje po kući i sam za sebe kaže da je „tatamata", dok žena sedi kod kuće, kuva i smeška se na muževljevu dominantnost. Reklame za banke često posežu za lepom, učtivom i staloženom ženom, koja treba da personifikuje beskrajno poverenje u banku. Primer je popularna reklama za kredite Rajfajzen banke, gde bankarska službenica na svako pitanje klijenata odgovara sa „može“ uz blazirani široki osmeh. Teško je zamislivo da bi ovakva uloga mogla biti dodeljena muškarcu. 
Lingvistkinja Džoana Tornborou (prema Sanderlend 2006: 206-211) navela je ključne elemente mizoginije (i seksizma) u reklamama na osnovu analize dva oglasa za rokovnike filofax. Naime, u oglasu namenjenom ženama, prisutno je direktno obraćanje u imperativu, žena u rečenici uvek ima sintaksičku funkciju objekta, kondicionalnim rečenicama sugeriše se da mora da ugađa mužu, ali ne i sebi, ona koristi leksičke kolokacije i semantička polja u vezi sa kućnim poslovima i brigom o deci, njena jedina briga su kućne obaveze i fizički izgled i njeno mesto je unutra. Muškarcima se reklama pak obraća potvrdnim rečenicama, kao da oni bolje razumeju suštinu, pa im se ne mora naređivati, muškarac uvek ima sintaksičku funkciju subjekta, koristi leksičke kolokacije i semantička polja u vezi sa poslom i zabavom, on putuje, radi odgovorne poslove i provodi se i njegovo mesto je napolju. Dakle, žene su podređene i smeštene u ne-javnu sferu delovanja, dok su muškarci nadređeni i javnost je njihov prostor. Pandan mogu biti muška i ženska verzija reklame za nivea1 i nivea 2 kremu, gde su žene zabrinute za lep izgled, a muškarci za snagu. Ovaj obrazac je u određenoj meri zastupljen u gotovo svim reklamama.

Globalna slika žene dolazi pre svega iz reklama i modnih magazina. U njima se žensko telo idealizuje i nameću se nedostižni standardi lepote, mladosti, elegancije, energičnosti, svežine, zavodljivosti. Za mušku publiku, takve slike mogu biti lepe i stimulativne, ali zažene mogu biti opasnost jer propagiraju nerealne parametre dobrog izgleda (Mekrobi 2009: 82, 99). Psihološki efekti ovakvih reklama mogu biti pogubni i odvesti žene u depresiju, stvoriti osećaj inferiornosti, a u težim slučajevima podstaći ih na anoreksiju, bulimiju i slične poremećaje u ishrani, sve to u potrazi za savršenom vitkošću koju reklame promovišu.

Reklame imaju izuzetnu ideološku snagu i uticaj na stvarnost. Njihov diskurs nije samo puki odraz realnosti, već on stvara i postulira ono što će u jeziku biti prihvaćeno kao normalno i poželjno (Ćopić 2008: 245). Mizogine reklame deluju na žene tako da se pitaju da li dobro izgledaju u odnosu na posmatrača (muškarca) i tako usvojeni identitet postaje im nametnuti okvir (Dragićević Šešić 2002: 397). 
Interesantno je da se ismevanje žene u reklamama prezentuje kao nešto komično i zabavno. U reklami za nektar sok, atraktivna devojka, čije su grudi u prvom planu, dolazi na takmičenje talenata i uspeva da privuče pažnju žirija tek pošto se skine u donji veš. Na njenu izjavu da želi da radi nešto da je „cela zemlja čuje“, daju joj posao glasa za automat tačnog vremena. U ovoj reklami, žena je prvo svedena na seksualni objekat, a potom izvrgnuta ruglu, što bi trebalo da ostvari komičan efekat.

U reklami za lav1 pivo, žena u manje od jednog minuta prelazi put od histerične ali atraktivne alapače, koja ne ume da vodi računa o sebi i svom psu, preko bespomoćne osobe kojoj treba zaštita muškarca, do pokorne domaćice koja mu kuva u znak zahvalnosti, a sve to je propraćeno muškim komentarima njegovih prijatelja „dobra nam kuma“. Slična reklama za isti brend (lav2) prikazuje površnu devojku opsednutu horoskopom i snalažljivog momka koji, umesto da prizna da je devica u horoskopu, kaže da je lav i time ostavlja utisak ,„šmekera“ i šarmira devojku.

Osim prema polu, žene su u televizijskim reklamama često stereotipno prikazane i prema godištu i socijalnom statusu. Starije žene su uvek domaćice i spremačice, ili čak zle tašte i svekrve koje samo prigovaraju i uvek imaju neku primedbu. Reklame za kozmetičke proizvode (ne)svesno se baziraju na ejdžizmu, odnosno diskriminaciji onih koji pripadaju trećem dobu (Jarić i Radović 2011: 53). Glavna ciljna grupa potrošačke civilizacije su mladi (Jarić i Radović 2011: 53), pa se i starijima nameće imperativ večne mladosti, lepote i svežine, naročito ženama (na primer, u reklamama za nivea3 i nivea4 kreme protiv bora, gde se potencira da mladu kožu ,,svi vole“ i da je potrebno sakriti godine mladolikim licem).

Reklama za igru na sreću loto1, iako duhovita, propagira stereotipe o ponašanju bogatih i siromašnih. Naime, bahata bogatašica dolazi kod svoje frizerke, koja uporno pokušava da joj kaže nešto važno, ali je ova ne sluša jer je opsednuta sobom. Frizerka je ljubazna i blaga i saopštava da je dobila sedmicu na lotou, međutim, mušterija je ignoriše i ućutkuje. Tada frizerka, samouverena zbog osvojenog novca, odseca bogatašici svu kosu 
i odlazi iz salona. Iako reklama ima elemente humora, njome se zapravo pokazuje da novac garantuje visok status i moć i da se samo bogati mogu ponašati po svojoj volji. Takođe, obe žene su prikazane kao delimično zle i bezosećajne.

Globalno tržište omogućava da se identični reklamni spotovi emituju širom sveta. Svetske korporacije jedan reklamni spot minimalno prilagođavaju određenom tržištu, pa se tako širom planete gledaju iste reklame na različitim jezicima. Postoje mišljenja da globalizacija pogoduje širenju feminističkog shvatanja (Jarić i Radović 2011: 50), ali može se reći i da globalizacija samo produbljuje površnost u razmatranju mizoginije i seksizma $u$ masovnim medijima.

U nekim slučajevima, prividno odsustvo jezičke poruke ima značajnu ubeđivačku ulogu u TV reklami. Ovu metodu, takozvanu „bockavu“ reklamu, koriste oglašivači koji izlaze na tržište sa novim brendom ili konceptom. „Bockava“ reklama podrazumeva prećutkivanje naziva proizvoda ili ćutanje o samom proizvodu (Beri i saradnici 1968: 290). Primer je reklamna kampanja supermarketa Lidl (lidl1, lidl2), koja je počela višednevnim emitovanjem spota o niskoj ženi i visokom muškarcu, da bi se u sledećoj reklami otkrilo da su to u stvari personifikacije niskih cena i visokog kvaliteta u ovom marketu. Ovakva vrsta televizijske reklame privlači pažnju jer stvara misteriju i intrigira potrošače da iščekuju rasplet. Međutim, seksistički ton ove reklame uzdrmao je javnost (Danas Online 2018), pa je bilo oštrih reakcija zbog tako banalizovane i omalovažavajuće predstave polova u marketinške svrhe. Iako se Lidl kasnije izvinio zbog mogućeg mizoginog tumačenja (Beta 2018), njihove naredne reklame za srpsko tržište sadržale su slične elemente (lidl2, lidl3). Žena u reklami uvek je locirana u kuhinji, kako kuva i tračari, ili je uz decu i žene u bašti, dok muškarac zida kuću, nosi ženu na ramenima i tako demonstrira svoju nadmoć. Takođe, svi ostali likovi u reklamama, bez obzira na pol, predstavljeni su kao tipični površni konzumeristi koje oduševljava samo kupovina. 


\subsection{Rušenje ili učvršćivanje stereotipa?}

Još jedan slučaj mizoginije u televizijskoj reklami koji je podigao prašinu bila je kampanja mobilne telefonije vip2 za tarife za mlade iz 2014. godine. Naime, ova reklama vrvi od stereotipa: mladi su prikazani kao neobuzdani i raskalašni, devojke su gole ili oskudno odevene, a vrhunac predstavlja scena u kojoj tri zgodne i doterane devojke mokre u pisoar. Ovaj „,voajersko-lascivni prikaz“ odgovara onom što se u teoriji vizuelnih komunikacija zove „pogled muškarca" (Cyber Wanderlust 2014). Iako je ova scena u reklami propraćena komentarom o „rušenju stereotipa“, njome se žena zapravo prikazuje na najstereotipniji mogući način, i to po meri muškarca. Iza reklame zapravo stoji mizogina poruka: ako želite da budete ravnopravne, morate da možete da postignete sve što i muškarci (Cyber Wanderlust 2014). Pored ove scene, celokupna marketinška kampanja ocenjena je kao diskriminatorska zbog izrazitog ejdžizma.

Većina reklama favorizuje muškarca i propagira patrijarhalne modele društvenog uređenja, predstavljajući ženu kao hraniteljicu, dušebrižnicu, spremačicu, kuvaricu, bespomoćnu i nesposobnu figuru opterećenu izgledom (Bašaragin 2013: 281, 288). Žena se stereotipno vezuje za imidž tradicionalnosti, koji je ograničava u izboru i delovanju kroz nametanje takozvanih prirođenih obaveza, koje ona mora da ispuni (Bašaragin 2013: 289). U tom smislu su interesantni eksperimenti u kojima su u tipične ženske uloge u mačističkim reklamama stavljeni muškarci, npr. u serijama fotografija Keli Kampton (Callie Compton) ili u projektu libanskog fotografa Elija Rezkalaha U paralelnom svetu. Njima je dokazano da je ljudima uglavnom neprijatno kada vide muškarca koji je sveden na seksualizovanu predstavu, dok im deluje normalno da se žena nađe u takvoj ulozi (Kampton 2014). Telo bi trebalo da bude veličano kao lepota, ali ne kao puka seksualizacija (Kampton 2014), te se tako za mnoge reklame može reći da zapravo samo eksploatišu ženu.

Svetski poznata reklama za pivo hajneken dovela je rodnu stereotipnost do apsurda. Naime, u ovoj reklami žene vrište od sreće jer imaju veliki garderober, a muškarci zato što imaju frižider 
pun piva. Ova reklama je pravi primer seksizma jer oba pola svodi na stereotip: o glupoj i lepoj ženi i pićem opsednutom muškarcu, a i poziva na zadovoljenje najnižih potreba. Slična novija reklama za jelen1 pivo takođe prikazuje stereotipe: muškarca koji peva kako je umoran od posla, dece, ženinog zvocanja, taštinog rođendana, pa zato pije pivo, igra fudbal i ide u kladionicu jer se uz pivo oseća „snažno“. Žene su samo dekor, vesele su kad su i muškarci veseli i uz njihovo muževno pevanje, one pevaju iskarikirano, kao da se prenemažu, o tome kako je muškarac „totalni heroj“ dok nosi gajbu piva. Još jedan izraziti primer seksizma je reklama za mobilnu telefoniju mts, gde se sugeriše da muškarcu „ne stoji“ da bude nežan i da tepa psu, dok je ženi takvo ponašanje urođeno. Ova reklama potvrđuje tezu Milene Dragićević Šešić da slika muškarca sa ženskim osobinama izaziva sažaljenje, a slika žene sa muškim osobinama averziju (2002: 373). Bilo kakvo pripisivanje ženskih osobina muškarcu i obratno u reklamama izaziva komičan efekat ili u gorem slučaju odbojnost.

Ima slučajeva kada su žene zaista predstavljene slobodno i mogu da se ponašaju jednako kao muškarci, a da to ne bude prikazano kao nešto odbojno. Primer je nešto starija reklama za jelen2 pivo, gde se devojka raduje kada vidi da stiže kamion s pivom, izlazi na ulicu, čeka muškarca koji vozi kamion, uzima pivo i u šali hvata momka za zadnjicu. Sve to prati opuštajuća muzika i vesela atmosfera, pa se stvara slika da je ovo ponašanje prirodno i spontano i da odgovara i muškarcima i ženama jer svi zajedno uživaju u pivu.

Žene se često prikazuju kao zavodnice (na primer, u reklami za parfem kavali), brbljive tračare (npr. reklama za grickalice pardon, gde koleginice ogovaraju jednu devojku, a kada se ona pojavi, tope se od ljubaznosti; reklama za supermarket Tempo, gde priglupe i radoznale žene zavide jedne drugima i utrkuju se koja će imati lepše sređenu baštu) ili domaćice bez ikakvih ambicija, posvećene isključivo kućnim obavezama (npr. reklame za deterdžente i sredstva za čišćenje). Muškarci dobijaju uloge uspešnih poslovnih ljudi (npr. reklama za automobil daster, mobilni telefon huavei), neodoljivih i šarmantnih plejboja (npr. reklama za parfem guči gilti ili piće šveps1 i šveps2, gde se sugeriše da su to proizvodi za zrele, 
odrasle i samouverene) ili lokalnih besposličara (mnoge reklame za pivo). Interesantno je da su istraživači u oblasti oglašavanja utvrdili da slika lepe devojke u reklami može prodati bilo koji proizvod, čak i ako između njene pojave i predmeta reklamiranja ne postoji nikakva logička veza (Beri i saradnici 1968: 286, 287). Takođe, ženski glasovi u reklamama (a i muški) najčešće imaju erotični, zavodljivi prizvuk jer se smatra da seksualizovan glas bolje prodaje proizvod. Korelacija glasa i proizvoda ogleda se i u odabiru naratora s obzirom na godine, pol, naglasak, dubinu glasa i sl. (Penok-Spek 2005: 975) ${ }^{4}$. Tako se u reklami za sladoled maksimo muškarac vizuelno predstavlja kao seksualni objekat, a žena auditivno, preko erotičnog glasa.

Prema studiji Constructing female identities through feminine hygiene TV commercials, reklame se mogu podeliti na one koje nude prividno objektivne informacije o proizvodu kako bi opravdale njegov odabir, i one koje se fokusiraju na njegove prednosti (Del SasRubio i Penok-Spek 2009a: 3, 15). U fokusu ove studije su televizijske reklame za higijenske uloške jer su u njima ženski likovi gotovo uvek prikazani maksimalno tipizirano. U prvoj grupi reklama, žene se muče sa neadekvatnim ulošcima, koji im umanjuju kvalitet i lepotu življenja, da bi potom umirujućim narativom bila opisana efikasnost novih uložaka i time automatski opravdana i racionalizovana njihova kupovina. Druga grupa reklama predstavlja prividnu glorifikaciju feminizma i ženstvenosti kroz mini-drame, prikazujući žene kao superheroje samo zato što su odabrale određeni brend uložaka, koji im postaje garancija za sreću i zadovoljstvo. Dobar primer je bilo koja reklama za always ili naturela uloške, ali i za mnoge kozmetičke preparate i šminku (npr. reklama za maskaru loreal).

U mnogim reklamama prikazuje se kako se muškarci i (češće) žene ulepšavaju ili menjaju ponašanje da bi se dopali suprotnom

4 Prema autorima Del Sas-Rubiju i Penok-Speku (2009b: 113, 114), glasovi reklamnih naratora razvrstavaju se prema tri kriterijuma: 1. socijalnom (obeležja porekla, socijalnog i obrazovnog statusa, profesije i društvene uloge); 2. fizičkom (godine, pol i zdravstveno stanje) i 3. psihološkom (tip ličnosti i raspoloženje). U zavisnosti od odlika proizvoda, tvorci reklama biraju adekvatan glas, ali on u najvećem broju slučajeva ima erotski prizvuk. 
polu (npr. reklama za pecivo seven days, u kojoj je konobar seksualni objekat zbog koga žene gube glavu, a on uživa u toj ulozi). Nekada su zastupljeni komični elementi, ali uglavnom se takve reklamne poruke baziraju na predrasudama o ponašanju i razmišljanju muškaraca i žena i stereotipnim odnosima, poput beskrajne romantike (npr. reklama za čokoladice mersi) i seksualnih aluzija (npr. reklama za malo lav pivo) s jedne strane, ili slike žene koja zvoca i muškarca koji je nezainteresovan i lenj, s druge strane (npr. reklama za loto2, u kojoj majka brine za dečje ocene, a otac samo misli na lutriju). Mnogi reklamni diskursi daju muškarcima uloge stručnjaka, lidera i dominantnih figura, dok žene prikazuju kao lepe, poslušne i podređene muškarcu u funkciji reklamnog dekora (Bašaragin 2013: 290).

\subsection{Diktat tržišta i poželjni identiteti}

Sociološkinja Renata Salecl u knjizi Tiranija izbora ističe da nas reklamne poruke stalno podsećaju da smo slobodni da radimo šta želimo sa svojim životom, a u stvari nas prisiljavaju da pravimo izbore po unapred zadatom modelu. U vezi sa reklamnim tehnikama, Salecl ističe poistovećivanje sa poznatim ličnostima u reklamama (2014: 51). Poznate žene se u reklamama najčešće pojavljuju samo da bi prikazale zanosan fizički izgled i da bi stavile svoju lepotu u službu proizvoda. Primer je reklama za nivea5 kremu sa glumicom Monikom Beluči, koja se emituje u celom svetu, ili za garnie1 farbe za kosu sa voditeljkom Marijom Kilibardom i glumicom Anđelkom Prpić. Jedna od retkih reklama gde je poznati muškarac predstavljen negativno (sa stereotipnim ženskim osobinama) jeste za kablovsku televiziju net tv plus, gde se glumac Emir Hadžihafizbegović kao zavisnik od televizije ponaša histerično i agresivno jer je nestao TV signal, dok je Lepa Brena smirena i nudi rešenje - prelazak kod novog provajdera. S obzirom na količinu površnosti sa kojom su ljudi predstavljeni u ovoj reklami, ona čak prevazilazi okvire mizoginije ili seksizma i prelazi u mizantropiju.

Potrošači su putem televizijskih reklama primorani da odaberu određeni proizvod kako bi postali deo neke poželjne grupe. Takvim 
ljubaznim ali imperativnim diskursom publici se obećava zadobijanje poželjnog kolektivnog identiteta (npr. reklamna kampanja mobilne telefonije vip3 i vip4). Često se ističe da je proizvod ili kompanija prvi, jedinstven ili revolucionaran u nečemu i da su njegovi korisnici ponosni i zadovoljni. Time se atributi proizvoda prenose na vlasnika proizvoda - potrošača (Šušnjić 1999: 164). Takve konstrukcije veoma su česte u reklamama za šminku, kozmetiku ili farmaceutske proizvode, najčešće namenjene ženama kako bi rešile sve svoje probleme (npr. reklama za šampon le petit marseillais ili za sredstvo za čišćenje lica garnie2). Tako se ženama sugeriše da će, zahvaljujući nekom preparatu, zadobiti poželjne osobine, odnosno lepotu i večnu mladost i da će udovoljiti muškoj pažnji.

Pozitivan primer upotrebe rodno osetljivog jezika možemo zapaziti u skorašnjoj reklami za loreal kremu, gde se kao autoritet struke pojavljuje žena, koja za sebe kaže da je doktorka, a ispod njenog imena stoji da je vlasnica jedne klinike za estetsku hirurgiju. Ipak, posle njenog pojavljivanja u kadru, muški glas govori o prednostima ove kreme, pa deluje kao da je doktorka samo lepo lice za reklamu. Sve u svemu, ipak treba pohvaliti upotrebu rodno senzitivnog jezika i razbijanje stereotipa o muškarcu kao jedinom stručnjaku i ženi kao poslušnom potrošaču.

\section{Zaključak}

Na osnovu analize reklama u ovom radu, može se zaključiti da je najčešći spoj seksualnog objekta i sluškinje

Reklame su dobar pokazatelj kako jezik može da održava i propagira određeni sistem vrednosti i ideologiju koja se prihvata kao uobičajena i ispravna. Kao što ima snagu da održava status quo po pitanju rodnih uloga, jezik televizijskih reklama može i da unese promene. Koliko će vremena proteći od promene u reklami do društvene promene ${ }^{5}$, zavisi od svake zajednice i odnosa koji u njoj vladaju.

5 Proces tokom koga se menjaju prihvaćena društvena pravila, strukture, društveni poredak i važeći vrednosni sistem (Jarić i Radović 2011: 50). 
Reklamni narativi prerastaju u kulturne i socijalne modele ponašanja u savremenom društvu. Jezik reklama odražava društveni poredak, oslikava tipizirane i stereotipne društvene odnose, i čak i kada formalno tvrdi suprotno, on samo učvršćuje već prihvaćene i ustaljene društvene uloge. Glavna opasnost zastupljenosti mizoginije u televizijskim reklamama leži u tome što se ona preko ovog prividno bezazlenog medija može preneti i u druge sfere života kao što su porodica, poslovno okruženje, politika i akademska zajednica. Najdrastičniji primer daje Zorica Mršević (2002: 509-511), koja u svom radu analizira udžbenik Kriminalistika (1979) dr Živojina Aleksića. Profesor Aleksić mizoginiji daje naučnu argumentaciju, prikazujući žene kao nesposobne i nepouzdane za učešće u bilo kakvom sudskom procesu. Pozivajući se na kvazipsihološke tvrdnje, on omalovažava žensku pamet i inteligenciju, što je nedopustivo, pogotovo u jednom zvaničnom udžbeniku ${ }^{6}$. Propagiranje takvih stavova dovodi do toga da se žene suočavaju sa takozvanim staklenim plafonom, odnosno nevidljivim preprekama koje im nameće društvo u kom dominiraju muškarci (Jarić i Radović 2011: 171).

Reklama kontroliše odluke kupca pod prividom mogućnosti izbora, a u stvari oglašivači kreiraju želje i potrebe prema svojim interesima. Televizijska reklama kao sredstvo komercijalnog reklamiranja deo je našeg kulturnog okruženja i vidljiv diskurs našeg vremena, doprinosi našoj socijalizaciji, izgradnji vrednosnih stavova i usvajanju određenih oblika ponašanja (Bašaragin 2013: 282). Reklamne strategije pokušavaju da dominiraju nad potrošačima, ali na njima je da nauče da budu kritički nastrojeni kupci kojima nije lako manipulisati. Jezički i psihološki mehanizmi koji se koriste u televizijskim reklamama mogu se sagledati na širem planu. U osnovi, oni su baza za sve vrste indoktrinacije, propagande i manipulacije u politici, ekonomiji, nauci i drugim sferama života. Zato je (prikriveno) prisustvo mizoginije i seksizma

6 Slične primere daju i Baćević i saradnici 2010 i Stojanović 2014, koji istražuju nepoštovanje rodne osetljivosti u akademskom i didaktičkom materijalu, kao i Valić Nedeljković 2008, koja analizira marginalizaciju političarki u izbornim kampanjama. 
u reklamama vrlo štetno i opasno i može imati ozbiljne posledice po društvene strukture i odnose. Društvo kao celina a i pojedinci moraju biti svesni toga i truditi se da izbegavaju seksistički diskurs i da doprinesu njegovom suzbijanju.

\section{LITERATURA}

Baćević i saradnici 2010: J. Baćević i saradnici, Analiza rodne dimenzije u visokoškolskom obrazovnom materijalu. Beograd: Program Ujedinjenih nacija za razvoj (UNDP), Sektor za inkluzivni razvoj.

Bašaragin 2013: M. Bašaragin, TV reklama kao ogledalo stereotipne mizoginije - kritička analiza reklamnog TV diskursa iz rodne perspektive. U: D. Valić Nedeljković, D. Pralica (ur.), Digitalne medijske tehnologije i društveno-obrazovne promene 3, Novi Sad: Filozofski fakultet, 281-292.

Beri i saradnici 1968: Dž. Beri, Dž. Bronovski i saradnici (ur.), Komunikacija i jezik -znaci, govor, pismo. Beograd/Ljubljana: Vuk Karadžić/ Mladinska knjiga.

Beta 2018: Beta, Lidl se izvinio zbog kampanje u Srbiji koja je percipirana kao ženomrzačka. Novosti, 5.10.2018, [https://www.novosti.rs/ vesti/naslovna/drustvo/aktuelno.290.html:753341-Lidl-se-izviniozbog-kampanje-u-Srbiji-koja-je-percipirana-kao-zenomrzacka]

Cyber Wanderlust 2014: Cyber Wanderlust, Fontana neravnopravnosti ili o tome kako žene pišaju. Labris, 6.11.2014, [http://arhiv2017.labris. org.rs/fontana-neravnopravnosti-ili-o-tome-kako-zene-pisaju/]

Ćopić 2008: H. Ćopić, Žene i jezik. U: A. Zaharijević (prir.), Neko je rekao feminizam? Beograd: Heinrich Böll Stiftung Regionalna kancelarija za Jugoistočnu Evropu, 236-247.

Danas Online 2018: Danas Online, Mihajlović poručila Lidlu: Žene u Srbiji se ne vrednuju kao roba. Danas, 5.10.2018, [https://www.danas.rs/ ekonomija/mihajlovic-porucila-lidlu-zene-u-srbiji-se-ne-vrednujukao-roba/]

Del Sas-Rubio i Penok-Spek 2009a: M. Del-Saz Rubio, B. PennockSpeck, Constructing female identities through feminine hygiene TV commercials. Journal of Pragmatics, 41(12), 2535-2556.

Del Sas-Rubio i Penok-Spek 2009b: M. Del Saz-Rubio, B. PennockSpeck, Voice-overs in standardized English and Spanish television commercials. Atlantis: Journal of the Spanish Association of AngloAmerican studies, 31(1), 111-127. 
Dragićević Šešić 2002: M. Dragićević Šešić, Mizoginija u obrascima masovne kulture. U: M. Blagojević (prir.), Mapiranje mizoginije u Srbiji: diskursi i prakse, Beograd: Asocijacija za žensku inicijativu, 371-404.

Gvozdanović 2010: J. Gvozdanović, Diskursi o rodnoj ravnopravnosti u jeziku. U: V. Vasić (ur.), Diskurs i diskursi: zbornik u čast Svenki Savić, Novi Sad: Filozofski fakultet, 225-229.

Irigare 1998: L. Irigaray, Linguistic sexes and genders. In: D. Cameron (ed.), The Feminist Critique of Language, London: Routledge, 119-123.

Jarić i Radović 2011: V. Jarić, N. Radović, Rečnik rodne ravnopravnosti. Beograd: Uprava za rodnu ravnopravnost Ministarstva rada i socijalne politike Republike Srbije.

Kampton 2014: C. Compton, Sex(ism) sells. Photo series, feature story, and artist statement, Calliecompton.weebly, [http://calliecompton. weebly.com/sexism-sells.html]

Kuzmanović Jovanović 2012: A. Kuzmanović Jovanović, Analiza postojećih normi za rodno osetljiv pristup u medijima. U: J. Filipović, A. Kuzmanović Jovanović (ur.), Vodičza rodno osetljiv pristup medijima u Srbiji: preporuke i dosadašnja praksa, Beograd: Ministarstvo rada, zapošljavanja i socijalne politike - Uprava za rodnu ravnopravnost, 41-69.

Kuzmanović Jovanović 2013: А. Кузмановић Јовановић, Језик и род. Дискурзивна конструкција родне идеологије. Београд: Чигоја штампа.

Mekrobi 2009: A. McRobbie, The after math of feminism: gender, culture and social change. London: SAGE.

Mils 2008: S. Mills, Language and sexism. Cambridge: Cambridge University Press.

Mršević 2020: Z. Mršević, Primer mizoginije u univerzitetskom udžbeniku: jedna žena - pola svedoka. U: M. Blagojević (prir.), Mapiranje mizoginije u Srbiji: diskursi i prakse, Beograd: Asocijacija za žensku inicijativu, 509-511.

Nenić 2008: I. Nenić, Matrica koja obećava? Predstavljanje i učešće žena u popularnoj kulturi. U: A. Zaharijević (prir.), Neko je rekao feminizam?, Beograd: Heinrich Böll Stiftung Regionalna kancelarija za Jugoistočnu Evropu, 263-273.

Penok-Spek 2005: B. Pennock-Speck, Styling the voice, selling the product. Studies in contrastive lingustics: Proceedings from the $4^{\text {th }}$ International Contrastive Lingustics Conference, 973-980, [https://www.academia. edu/2987987/Styling_the_voice_selling_the_product]

Piler 2003: I. Piller, Advertising as a site of language contact. Annual Review of Applied Lingustics, 23, 170-183. 
Rezkalah 2018: E. Rezkallah, In a parallel universe Elirezkallah, 16.01.2018, [http://www.elirezkallah.com/inaparalleluniverse]

Salecl 2014: R. Salecl, Tiranija izbora. Beograd: Arhipelag.

Sanderlend 2006: J. Sunderland, Language and Gender: an advanced resource book. London: Routledge.

Savić 2002: S. Savić, Seksizam u jeziku - politika omalovažavanja. U: M. Blagojević (prir.), Mapiranje mizoginije u Srbiji: diskursi i prakse, Beograd: Asocijacija za žensku inicijativu, 65-86.

Silaški 2010: N. Silaški, Konceptualizacija lepote - kritička analiza medijskog diskursa upućenog ženama. U: V. Vasić (ur.), Diskurs i diskursi: zbornik u čast Svenki Savić, Novi Sad: Filozofski fakultet, 323-336.

Stojanović 2014: I. Stojanović, Seksizam, rodni stereotipi i uloge u tri udžbenika španskog kao stranog jezika: kritička analiza fotografija i ilustracija. Master rad, Filološki fakultet Univerziteta u Beogradu, [https://www.academia.edu/5864067/Seksizam_rodni_stereotipi_i_ uloge_u_tri_ud\%C5\%BEbenika_\%C5\%A1panskog_kao_stranog_ jezika_Kriti\%C4\%8Dka_analiza_fotografija_i_ilustracija]

Šušnjić 1999: Đ. Šušnjić, Ribari ljudskih duša. Beograd: Čigoja štampa.

Valić Nedeljković 2008: D. Valić Nedeljković (ur.), Kandidatkinje: monitoring prisustva žena kandidatkinja u medijima tokom predizbornih kampanja za lokalne i pokrajinske izbore u 2008. Novi Sad: Novosadska novinarska škola.

Višnjić i Mirosavljević 2008: J. Višnjić, M. Mirosavljević, Problem reprezentacije roda u medijima. U: A. Zaharijević (prir.), Neko je rekao feminizam?, Beograd: Heinrich Böll Stiftung Regionalna kancelarija za Jugoistočnu Evropu, 248-262. 


\title{
Ana Huber
}

\section{MISOGINIA Y SEXISMO EN LOS ANUNCIOS EN TELEVISIONES SERBIAS}

\begin{abstract}
Resumen
El tema de este trabajo es la misoginia y el sexismo en los anuncios televisivos que abundan en estereotipos de género. El corpus analizado consta de anuncios emitidos en Serbia en cadenas televisivas con la cobertura nacional entre otoño de 2018 y el verano de 2020, con excepción de varios anuncios un poco más antiguos que sirven de ejemplo ilustrativo. Se intenta explicar, desde el punto de vista feminista, con cuáles recursos lingüísticos y persuasivos se crea un cierto grado de la discriminación de género en los vídeos comerciales de televisión. El objetivo de este trabajo es facilitar las pruebas de la existencia de discursos y efectos visuales misóginos y sexistas en los anuncios televisivos a través de un análisis cualitativo del corpus de los anuncios elegidos, incluso cuando aparentemente se propaga una actitud emancipadora con respecto a la cuestión femenina. Además de sexismo y estereotipos, se analiza la presencia de la discriminación por edad y estatus social. Se investiga cómo el lenguaje de los anuncios refleja el orden social y manifiesta las relaciones sociales tipificadas y estereotipadas y si, incluso cuando formalmente afirma lo contrario, solamente corrobora los roles de género ya establecidos. Los resultados del análisis comprueban que los anuncios tienen un efecto psicológico y social muy impactante y que crean los modelos de comportamiento e ideologías preferentes.
\end{abstract}

Palabras clave: misoginia, sexismo, anuncios televisivos, feminismo, estereotipos de género, roles de género. 


\section{Dodatak. Linkovi reklama ${ }^{7}$}

Biomed 4: https://www.youtube.com/watch?v=PYcw0GqRjZE Naksi: https://www.youtube.com/watch?v=bDYqSmos-Uc Tensilen: https://www.youtube.com/watch?v=j5uH40Tuujw Idea: https://www.youtube.com/watch?v=4KoycWdvUx4 Mivela: https://www.youtube.com/watch?v=em9wb7TTnxc Herbafast fajber: https://www.youtube.com/watch?v=_4oU92zrS8I Limes: https://www.youtube.com/watch?v=6DfMjdLVAE8 Otpor: https://www.youtube.com/watch?v=T3Vjc5awCnA Vip1: https://www.youtube.com/watch?v=cQcW9qhA0es Vip2: https://www.youtube.com/watch?v=17UU9Z2pHLM Vip3: https://www.youtube.com/watch?v=ZFvj5FMYOrY Vip4: https://www.youtube.com/watch?v=Qi4C2tQSyT4 Rajfajzen: https://www.youtube.com/watch?v=mOICRGcxZ60 Nivea1: https://www.youtube.com/watch?v=2tPQEPF54do Nivea2: https://www.youtube.com/watch?v=niy5zhJbla0 Nivea3: https://www.youtube.com/watch?v=GJtAegMNnQg Nivea4: https://www.youtube.com/watch?v=GyvX_oeTztQ Nivea5: https://www.youtube.com/watch?v=LpqeqRdQ-94 Nektar: https://www.youtube.com/watch?v=0Yuu650R4-Y Lav1: https://www.youtube.com/watch?v=_yQMAkDcuj4 Lav2: https://www.youtube.com/watch?v=h-17ENg0zR0 Loto1: https://www.youtube.com/watch?v=3wmTQpccchU Loto2: https://www.youtube.com/watch?v=AYJCvPT0GrY Lidl1: https://www.youtube.com/watch?v=ponxxAEejEA Lidl2: https://www.youtube.com/watch?v=SL82tBLBerY Lidl3: https://www.youtube.com/watch?v=03IrJ_4elLo Hajneken: https://www.youtube.com/watch?v=S1ZZreXEqSY Jelen1: https://www.youtube.com/watch?v=ZETmnT0cE4o Jelen2: https://www.youtube.com/watch?v=Ty-OwR-RYnU Mts: https://www.youtube.com/watch?v=n01nSTgx6KU Kavali: https://www.youtube.com/watch?v=vr0qBMtS_4c Pardon: https://www.youtube.com/watch?v=RzAhPybI5tU Tempo: https://www.youtube.com/watch?v=ZEQ7UQTaj0Q

7 Linkovi su navedeni redom kojim se reklame pominju u radu. U slučajevima kada na internetu nismo uspeli da nađemo verziju reklame na srpskom, naveli smo linkove ka reklami na nekom drugom jeziku kako ne bi izostao primer. Linkovi su preuzeti i ažurirani 17.08.2020. 
Daster: https://www.youtube.com/watch?v=-t2CvngFDAQ Huavei: https://www.youtube.com/watch?v=s2fLaIUVvYA Guči: https://www.youtube.com/watch?v=DXGxOmsWtiA Šveps1: https://www.youtube.com/watch?v=QoUEbRIBZEk Šveps2: https://www.youtube.com/watch?v=_qiMNYYqIdg Maksimo: https://www.youtube.com/watch?v=MvurefQ8kbc Always: https://www.youtube.com/watch?v=kPgw72lEWMA Naturela: https://www.youtube.com/watch?v=SuQJFiPFIAg Loreal maskara: https://www.youtube.com/watch?v=4F_jffezJxs Seven days: https://www.youtube.com/watch?v=WuV0gP256N8 Mersi: https://www.youtube.com/watch?v=7JJIIZEa7T4 Lav mini: https://www.youtube.com/watch?v=lroeRb90kJQ Garnie1: https://www.youtube.com/watch?v=mKI5a-oJJms Garnie2: https://www.youtube.com/watch?v=d8SFVLYpUa0 NetTv plus: https://www.youtube.com/watch?v=BcmTyy5nj-o Le Petit Marseillais: https://www.youtube.com/watch?v=kVgChwPlsbA Loreal: https://www.youtube.com/watch?v=F7yendG97Xo 